\title{
Recuperação de áreas degradadas e mineração: análise da produção científica internacional na Web of Science (WoS)
}

A exploração dos recursos naturais provoca inúmeras consequências sociais e ambientais aos ecossistemas, comprometendo as condições do solo e reduzindo a possibilidade de regeneração natural na área explorada. Assim, este artigo tem como objetivo analisar o comportamento bibliométrico da produção científica internacional sobre recuperação de áreas degradadas pela mineração. Trata-se de uma pesquisa exploratório-descritiva, com abordagem qualitativa, realizada na base de dados Web of Science. Para tanto, utilizou-se o software VosViewer para a análise das redes bibliométricas que caracterizam a produção internacional acerca do referido tema. O período selecionado para a busca foi de 1945 a 2020. Foram utilizados os termos environmental restoration, environmental recovery, recovery of degraded áreas, soil recovery e revegetated areas em combinação com o (tópico) termo mining. Estes foram pesquisados em títulos, resumo e palavraschave do autor das publicações contidas nas coleções mencionadas. Quanto às obras qualificadas como as de impacto no campo, o Fator $\mathrm{H}$ ( $\mathrm{h}$-index) apontou para 18 publicações, incluindo-se apenas os documentos de tipo article e review. Os resultados apontam para formações de clusters de autores, instituições e países. Os termos mais destacados giram em torno das palavras-chave elencadas como foco do estudo.

Palavras-chave: Recuperação de áreas degradadas; Mineração; Bibliometria.

\section{Recovery of degraded areas and mining: analysis of international scientific production on the Web of Science (WoS)}

\begin{abstract}
The exploitation of natural resources has numerous social and environmental consequences for ecosystems, compromising soil conditions and reducing the possibility of natural regeneration in the exploited area. Thus, this article aims to analyze the bibliometric behavior of international scientific production on the recovery of areas degraded by mining. This is an exploratory-descriptive research, with a qualitative approach, carried out in the Web of Science database. For this, the VosViewer software was used to analyze the bibliometric networks that characterize international production on the subject. The period selected for the research was from 1945 to 2020 . The terms environmental restoration, environmental recovery, recovery of degraded areas, soil recovery and revegetated areas were used in combination with the (topic) term mining. These were searched for titles, abstracts and keywords of the author of the publications contained in the mentioned collections. As for the work qualified as impactful on the field, the Factor $\mathrm{H}$ (hindex) pointed to 18 publications, including only article and review documents. The results point to the formation of clusters of authors, institutions and countries. When including only articles and review documents prominent terms revolve around the keywords listed as the focus of the study.
\end{abstract}

Keywords: Recovery of degraded areas; Mining; Bibliometrics.

Topic: Uso de Recursos Naturais

Reviewed anonymously in the process of blind peer.
Received: 06/12/2020

Approved: 23/12/2020
Marcos Macri Olivera (iD

Universidade Federal de Campina Grande, Brasil http://lattes.cnpq.br/6161476125979644 http://orcid.org/0000-0001-9446-4727 macri.ccjs@gmail.com

Nadege da Silva Dantas

Universidade Federal de Campina Grande, Brasil http://lattes.cnpq.br/0463506734595102

http://orcid.org/0000-0002-1523-4884

nadege.dantas@gmail.com

Sergio Murilo Santos de Araújo (iD

Universidade Federal de Campina Grande, Brasil

http://lattes.cnpq.br/6693832655779279

http://orcid.org/0000-0001-9599-4383

sergiomurilosa.ufcg@gmail.com
Referencing this:

OLIVEIRA, M. M.; DANTAS, N. S.; ARAÚJO, S. M. S.. Recuperação de áreas degradadas e mineração: análise da produção científica internacional na Web of Science (WoS). Revista Ibero Americana de Ciências Ambientais, v.11, n.7, p.672-689, 2020. DOI: http://doi.org/10.6008/CBPC2179-6858.2020.007.0052 


\section{INTRODUÇÃO}

Há milhares de anos nosso planeta vem sofrendo com as ações antrópicas. O homem agride a natureza por meio de diversas atividades, a fim de explorar diferentes ecossistemas. A capacidade de adaptação aos diferentes habitats, fez do homem o principal responsável pela degradação do meio ambiente. Com o desenvolvimento da ciência, tecnologia e da sociedade, as necessidades humanas pelos recursos naturais aumentaram de maneira drástica, causando o comprometimento da capacidade de recuperação ambiental (LOPES, 2013).

Diante desta situação, torna-se de vital importância a recuperação das áreas degradadas, devido às consequências negativas causadas pela deterioração dos ecossistemas (TATSCH, 2011). O procedimento de exploração de minérios causa numerosas consequências socioambientais resultantes dos atributos específicos desta atividade econômica. Assim, a extração provoca mudanças no espaço geográfico a ser alterado, a extensão da área a ser explorada, erosão do solo, a retirada da cobertura vegetal, deslocamento da macro fauna da área, o período de atividade da jazida, a grandeza de aplicação econômica, dentre outras das quais transcorrem várias consequências sociais e ambientais nos locais explorados (MOREIRA, 2002). Além disso, com o crescimento da população, o aumento na expectativa de vida e a tendência à padronização do consumo, a necessidade de utilização dos recursos naturais tem aumentado indiscriminadamente, o que compromete a qualidade de vida e a sobrevivência das futuras gerações.

Conforme dados da Global Assessment of soil Degradation (GLASOD), no mundo, 1.964 × 106 hectares encontram-se degradados (OLDEMAN et al., 1998). Esse valor corresponde a $13 \%$ da Terra. Os autores apresentam cinco principais causas para a degradação, a saber: o desmatamento, o manejo inadequado da agricultura, o superpastejo, a superexploração da vegetação para combustível e a atividade industrial (KOBIYAMA et al., 2001).

Há autores que apontam outras atividades que agridem o meio ambiente e provocam impactos negativos ao nosso planeta. Na visão de Machado (1995), várias atividades antrópicas vêm criando problemas ambientais, no uso do solo e subsolo, além das atividades de mineração, entre as quais se destacam: a urbanização desordenada, agricultura, pecuária, construção de barragens, visando a geração de hidroeletricidade, uso não controlado de água subterrânea, além de outras. O autor considera que a mineração não é a atividade econômica mais agressiva ao meio ambiente e defende que outras atividades, tais como a agricultura, a petroquímica, a siderurgia, as grandes barragens e a própria urbanização, têm características mais impactantes do que a mineração'.

Este artigo tem como objetivo analisar o comportamento bibliométrico da produção científica internacional sobre a temática Recuperação de áreas degradadas em associação com a mineração, indexada na base de dados Web of Science. O principal objetivo foi conhecer o cenário global sobre a temática anunciada, além de analisar, via técnicas avaliativas e relacionais, as redes que caracterizam a produção internacional acerca do referido tema. Por fim, pretende-se auxiliar os estudiosos na área a identificarem publicações científicas para a produção de futuras pesquisas. 


\section{REVISÃO TEÓRICA}

Os empreendimentos de mineração contribuem para o desenvolvimento social, todavia, respondem também pelos impactos, muitas vezes, irreversíveis sobre o meio ambiente (LIMA, 2012). A recuperação das áreas degradadas pela mineração representa um desafio que demanda a intervenção humana para auxiliar o ecossistema degradado a recuperar sua capacidade de resiliência. Para tanto, a literatura recomenda o plantio de espécies florestais nativas para reativar os processos ecológicos que mantêm as funcionalidades ecossistêmicos e o equilíbrio ambiental dessas áreas degradadas (RESENDE et al., 2010).

Observa-se que os danos causados ao meio ambiente, por consequência dessa atividade, não são poucos. De acordo com Mechi et al. (2010), o principal é o desequilíbrio dos ecossistemas, além da destruição do habitat natural dos animais e o escorregamento da fauna. Esses problemas poderão atingir também a saúde humana, causando doenças decorrentes da poluição, principalmente da água e do ar. Ainda para os autores, a maioria das atividades de mineração provoca a extinção da vegetação e o impedimento de sua regeneração.

Por seus impactos, muitas vezes irreversíveis, a mineração é a única atividade cuja obrigação de Recuperação de Áreas Degradadas (RAD) é imposta pela Constituição Federal do Brasil de 1988 (FARIAS, 2016), ao estabelecer em seu artigo 225 que todas as empresas de mineração têm obrigação de apresentar ao órgão ambiental um Plano de Recuperação de Áreas Degradadas (PRAD), documento que preconiza a adoção de procedimentos para estabelecer ou restabelecer a cobertura vegetal nas áreas degradadas, prática conhecida como revegetação (ALMEIDA et al., 2005). Porém, a implementação das medidas propostas nos PRADs não se concretizam em função das dificuldades relacionadas ao manejo do solo e das plantas, que chegam a comprometer o sucesso da revegetação.

Vale salientar que a legislação brasileira tem como base o Código de Mineração (Decreto-Lei Federal 227/67), com suas sucessivas alterações a atualizações posteriores. A obrigatoriedade de recuperação dos impactos ambientais está prevista, também, na Lei n. 6.938/81 e nos Decretos Regulamentadores n. 97.632/89 e 99.274/90. Esses documentos estabelecem as regras que exigem do empreendedor o retorno da área a um estado próximo ao original. O empreendedor tema responsabilidade de propor o aproveitamento futuro da área, de acordo com as possibilidades de uso do solo (NERI et al., 2012; FARIAS, 2016).

Além disso, a Instrução Normativa ICMBIO n¹1 de 2014 estabelece os principais procedimentos para elaboração de um PRAD. Esse documento acompanha o Estudo de Impacto Ambiental no licenciamento exigido pelo Órgão Federal Ambiental, o Instituto Brasileiro do Meio Ambiente e dos Recursos Naturais Renováveis (IBAMA), com o objetivo de planejamento da recuperação da área, durante e após operação da mina. As diretrizes que orientam a elaboração e apresentação de projeto de reabilitação de áreas degradadas pela mineração, estão previstas na ABNT, através da NBR 13030 que visa obter subsídios técnicos que possibilitem a manutenção e/ou melhoria da qualidade ambiental, independente da fase de instalação do projeto (ABNT, 1999). 
Observa-se, portanto, que, no conjunto da legislação ambiental minerária brasileira, existem várias orientações legais quanto aos objetivos, implantação de estruturas e remodelação de áreas degradadas, contudo sem indicação de métodos ou tecnologias específicas apropriadas. Quanto às estruturas de uso indispensável no processo de recuperação de áreas, também não são encontradas determinações construtivas mínimas (ARAÚJO, 2016).

A especificação do tipo de manejo de cada etapa do processo de recuperação tem sido uma exigência para o licenciamento ambiental (MARCUS, 1997; BRASIL, 2001; FEPAM, 2012). Para tanto, a implantação de métodos mais específicos para a minimização dos impactos da mineração, faz-se necessário, tanto na legislação vigente, quanto em materiais informativos, bem como de um manejo diferenciado durante a operação da mina, visando maior eficácia no seu fechamento e recuperação. A esse respeito, autores sugerem que a prática da consorciação entre esses métodos seja mais indicada (PEREIRA, 2001; MORETTO, 2012).

De acordo com Moura (2015), as principais ações para que as áreas degradadas possam voltar a ser produtivas consistem no desenvolvimento e estabelecimento de sistemas de manejo do solo seguido da revegetação do local de maneira, inclusive, a propiciar o retorno da fauna. A esse respeito, Chaer et al. (2011), afirmam que, dependendo do estágio de degradação das áreas de mineração, a revegetação, por processos naturais, torna-se difícil, dessa forma, a intervenção antrópica faz-se necessária no processo de melhoria do ambiente químico-físico-biológico do solo e pela seleção e introdução de espécies adaptadas e capazes de restabelecer os processos de sucessão natural.

Devido à necessidade de intervenção humana e alteração das características ambientais da região, para que a extração mineral seja efetivada, o empreendimento minerário acarreta o surgimento de áreas degradadas durante e ao final da exploração, uma vez que o minério extraído da natureza não retorna ao seu local de origem. As principais ações para que as áreas degradadas possam voltar a ser produtivas consiste no desenvolvimento e estabelecimento de sistemas de manejo do solo seguido da revegetação do local de maneira a propiciar o retorno da fauna.

Os processos de recuperação de uma área degradada podem ser iniciados através de diferentes métodos, os principais são por meio de medidas de intervenção do homem, através do reflorestamento com mudas e manejo adequado, regeneração natural da vegetação ainda existente. A rapidez da recuperação via regeneração natural dependerá do processo de intemperização dos solos, da proximidade de árvores porta sementes e do banco de sementes (SALES et al., 2008).

Na visão de Shrestha et al. (2010), para que a biodiversidade de um ecossistema retorne a uma condição saudável, é necessário o equilíbrio combinado com características físicas, químicas e biológicas do solo, por meio de processos eficazes que impliquem na sua auto sustentabilidade (SHRESTHA et al., 2010).

Essa preocupação é apresentada, também, por outros autores, como Bengtsson et al. (2003) e Balieiro (2017) ao afirmarem que, em terras severamente degradadas, como áreas de mineração, a perda de "memória ecológica" local pode resultar em altos custos de reabilitação, uma vez que a memória ecológica é sugerida para dificultar o desenvolvimento natural de comunidades vegetais simples ou complexas. 
Embora, em alguns casos, a restauração da qualidade do solo pode ocorrer mais rápido do que a comunidade da vegetação (PARROTTA et al., 1999; SILVA et al., 2013; BALIERO, 2017).

\section{MATERIAIS E MÉTODOS}

Em termos de caracterização, este estudo se posiciona como exploratório e descritivo, tendo em vista que almejou proporcionar uma visão geral, de tipo aproximativo, ao mesmo tempo em que procurou descrever as características do objeto de estudo (GIL, 2008). Sua natureza é bibliométrica, uma vez que procurou investigar a evolução do tema em foco, por meio da avaliação de performance de publicação de autores e instituições, bem como mapeando a estrutura do campo de conhecimento por meio de dados (KOSEOGLU, 2016). Dessa forma, utilizou-se técnicas avaliativas (medidas de produtividade e métricas de impacto) e técnicas relacionais (coautoria e coocorrência).

O método foi desenvolvido em quatro etapas. A primeira consistiu na escolha dos termos que comporiam o tema central da pesquisa. Escolheram-se termos que se caracterizam como conceitos basilares da disciplina Recuperação de Áreas Degradadas (RAD), do Programa de Pós Graduação em Engenharia e Gestão de Recursos Naturais, da Universidade Federal de Campina Grande (UFCG). Em seguida, escolheu-se uma atividade fortemente associada ao campo de RAD: a mineração.

A segunda etapa do método consistiu na coleta dos dados. Esta foi realizada na base Web of Science, especificamente utilizando as coleções Science Citation Index Expanded (SCI-EXPANDED), Social Sciences Citation Index (SSCI) e Emerging Sources Citation Index (ESCI). A coleta foi realizada em 01/02/2020. Como tópicos de busca foram utilizados os termos environmental restoration, environmental recovery, recovery of degraded áreas, soil recovery e revegetated areas em combinação com o (tópico) termo mining. Estes foram pesquisados em títulos, resumo e palavras-chave do autor das publicações contidas nas coleções mencionadas. O período selecionado da busca foi de 1945 a 2020 (todo o disponível). Tal procedimento resultou em 103 publicações identificadas. Realizou-se ainda um refinamento: foram excluídas as categorias hospitality leisure sport tourism e medicine research experimental (por serem consideradas fora do escopo de trabalho da disciplina originária do estudo) e foram incluídos apenas os documentos de tipo article e review. Dessa maneira, o total de publicações encontradas foi 99.

Em seguida, foi realizado o tratamento dos dados. Para a execução das técnicas avaliativas, os dados foram tabulados e organizados utilizando a ferramenta Clarivate Analytics (disponível na Web of Science). Foram gerados gráficos descrevendo publicações por áreas, por ano, por periódicos, por organizações, por países e por idiomas. As publicações também foram ranqueadas a partir do cit. score e classificadas de acordo com seu Fator $\mathrm{H}(H$-Index) para identificar quais autores e, por consequência, obras possuem impacto na área de estudo. Hirsch (2005) propõe que um pesquisador possui Fator $\mathrm{H}$ se seu $\mathrm{Np}$ (número de publicações) tiver um mínimo de $h$ citações, cada um deles, e, os demais estudos, tiverem menos ou iguais citações cada um. Ainda, o Fator $\mathrm{H}$ foi utilizado em dois momentos: no primeiro constatou-se o $\mathrm{H}$-index levando em consideração as citações dentro e fora do grupo de publicações identificado no procedimento de coleta de dados e, em um segundo momento, verificou-se o $\mathrm{H}$-index considerando as citações apenas dentro do grupo. 
Quanto às técnicas relacionais, utilizou-se o software VOSviewer version 1.6.12. O referido programa é um software que oferece ferramentas para construção e visualização de redes bibliométricas (VAN ECK et al., 2017) e, a partir deste, foram formulados mapas bibliométricos com base nos tipos e unidades de análise listados no quadro 1.

Quadro 1: Definição dos parâmetros de corte no VOSviewer.

\begin{tabular}{|l|l|l|}
\hline PARÂMETROS & DESCRIÇÃO \\
\hline $\begin{array}{l}\text { Tipo de } \\
\text { Análise }\end{array}$ & $\begin{array}{l}\text { Unidade de } \\
\text { Análise }\end{array}$ & $\begin{array}{l}\text { Relação de força que ocorre quando, em síntese, autores participam de publicações em } \\
\text { parceria. }\end{array}$ \\
\hline Co-authorship & Authors & $\begin{array}{l}\text { Relação de força que ocorre quando, em síntese, organizações participam de publicações } \\
\text { em parceria. }\end{array}$ \\
\hline Co-authorship & Organizations & $\begin{array}{l}\text { Relação de força que ocorre quando, em síntese, países participam de publicações em } \\
\text { parceria. }\end{array}$ \\
\hline Co-occurrence & All Keywords & Relação de força e frequência entre palavras-chave (termos). \\
\hline
\end{tabular}

Fonte: Adaptado de Van Eck et al. (2017).

Os mapas gerados pelo software ora mencionado enfatizam a formação de clusters. Estes, no contexto da análise realizada, caracterizam-se como conglomerados de cooperação, em que os membros apontados efetivaram algum nível de 'contato'.

Por fim, realizou-se uma análise qualitativa a partir das técnicas avaliativas e relacionais aplicadas na etapa anterior. Investigaram-se os dados mais destacados e procurou-se evidenciar aspectos relevantes, assim como concluir sobre as relações de colaboração e clusterização dos termos componentes mais alinhados no campo em estudo.

\section{RESULTADOS E DISCUSSÃO}

A pesquisa realizada localizou 99 publicações. A soma do número de citações foi 1.496, uma média de 15,11 citações por publicação. O artigo mais antigo é Recolonization of Regenerating Open Forest by Terrestrial Lizards Following Sand Mining, escrito por Laurie E. Twigg e Barry J. Fox e publicado no Australian Journal of Ecology, em Junho de 1991. De forma mais detalhada, a evolução do número de publicações por ano é apresentada na figura 1.

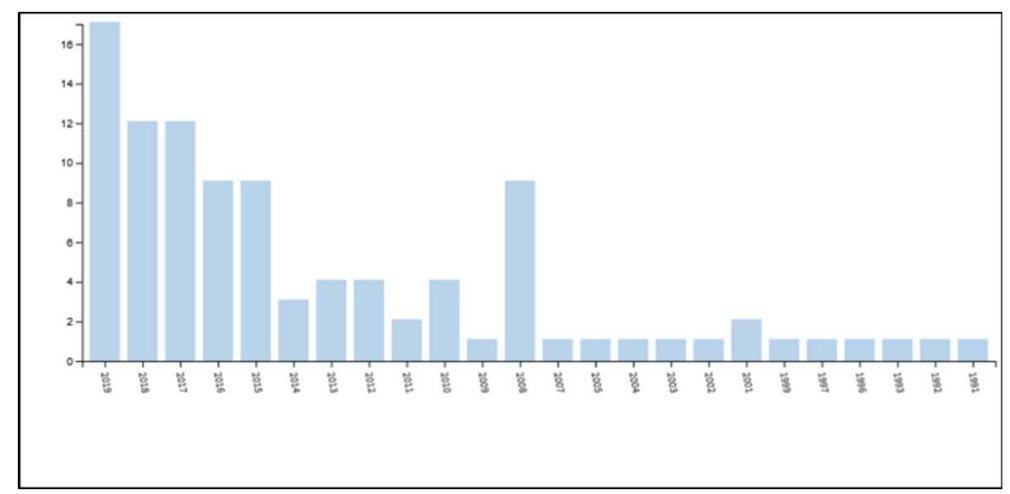

Figura 1: Quantidade de publicações por ano. Fonte: Web of Science (2020).

Foi possível observar que o número (mínimo) de publicações se manteve estável entre 1991 e 2007. Em 2008, parecia ter ocorrido um ponto de inflexão, com um aumento significativo na quantidade de artigos. 
Todavia, não se concretizou uma tendência nesse ponto e as publiçações voltaram a um patamar intermediário. A partir de 2015 o número de publicações voltou a crescer, alcançando o volume de 2008, e a evolução nos anos seguintes parece indicar uma tendência de crescimento de interesse na área. Em 2019 a quantidade de publicações superou em mais de $40 \%$ o volume de 2017 e 2018 - anos que detinham a maior quantidade de artigos publicados. Com relação às áreas das publicações investigadas, a figura 2 indica as dez áreas com mais artigos publicados.

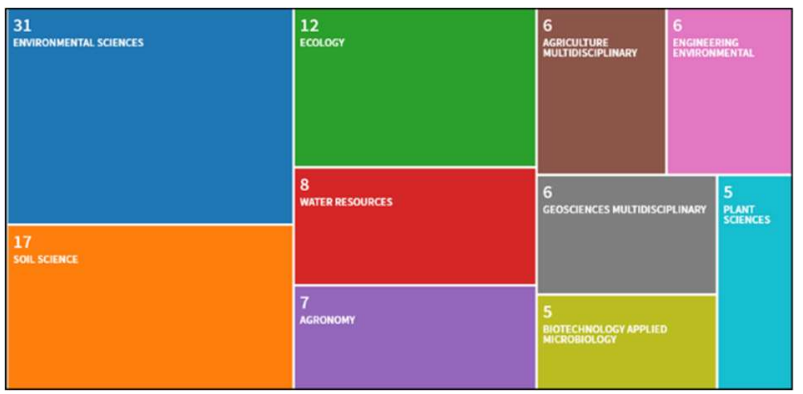

Figura 2: Quantidade de publicações por área. Fonte: Web of Science (2020).

A área com mais publicações é Environmental Sciences, seguida por Soil Science e Ecology. As três comportam mais de $60 \%$ das publicações localizadas. As demais áreas, entre as 10 com mais publicações, com menor frequência, estão associadas ao meio-ambiente. No total, 41 áreas publicaram artigos que envolvem o tema RAD e a mineração, incluindo áreas com escopos bem restritos como Engineering Geological e Mathematical Computational Biology, por exemplo. Se existe uma grande concentração de publicações por área, o resultado da avaliação por periódicos é diferente, conforme mostra a figura 3.

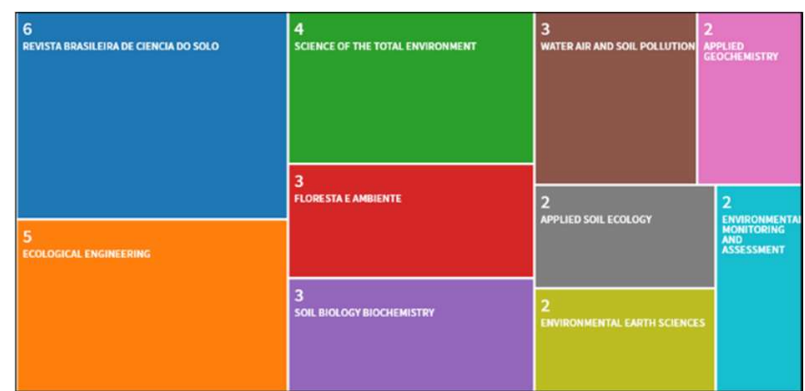

Figura 3: Periódicos com mais publicações

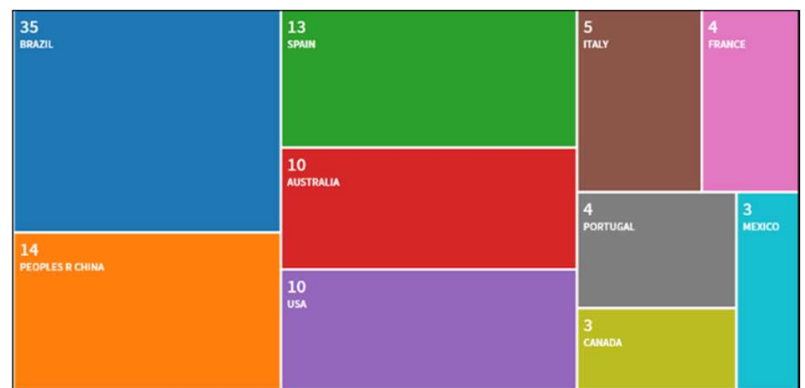

Figura 4: Artigos publicados por país

Fonte: Web of Science (2020)

A Revista Brasileira de Ciência do Solo é o periódico com mais publicações na área objeto deste estudo. Trata-se de uma revista editada pela Sociedade Brasileira de Ciência do Solo (SBCS), publicada desde 1977 e qualificada na CAPES com Qualis A2 em Agricultural Sciences. Percebe-se que existe grande dispersão na quantidade de publicações por revista, com os 10 periódicos com maior frequência de publicações, recebendo pouco mais de $30 \%$ do total de artigos e outros 66 periódicos publicando, ao menos, um artigo sobre o tema. Constatou-se, ainda, que, das 10 revistas com mais publicações, metade está sediada na Holanda, duas no Brasil, duas na Inglaterra e uma nos EUA. A frequência de publicações por país é abordada na figura 4.

O Brasil é líder destacado em publicações. Junto com a China, praticamente, são responsáveis pela metade dos artigos localizados na pesquisa. Mais de 50\% dos artigos publicados têm origem em países da 
América e, ao menos, mais de $25 \%$ foram escritos por autores de países europeus. Com 10 publicações, EUA é apenas o 50 país com mais artigos escritos. De forma geral, a maioria dos autores desses artigos se encontra vinculado a alguma organização. Nesse sentido, a figura 5 apresenta as organizações com autores que mais publicaram no período avaliado:

Corroborando com análise de quantidade de publicações por país, as organizações brasileiras são as mais frequentes no grupo de dez organizações que contêm autores que publicaram artigos tratando da temática abordada neste estudo. A EMBRAPA e a Universidade Federal de Lavras são as duas com mais publicações e, somando-se à Universidade Federal de Santa Catarina e Universidade Federal de Viçosa, o Brasil possui quatro das cinco organizações que mais publicam sobre a temática. Entre as dez primeiras, metade são brasileiras e três chinesas. Outras 17 organizações brasileiras têm autores que publicaram artigos, totalizando 22. Por razões óbvias, o idioma das publicações merece atenção. Tal análise pode ser feita observando os dados colocados na figura 6.

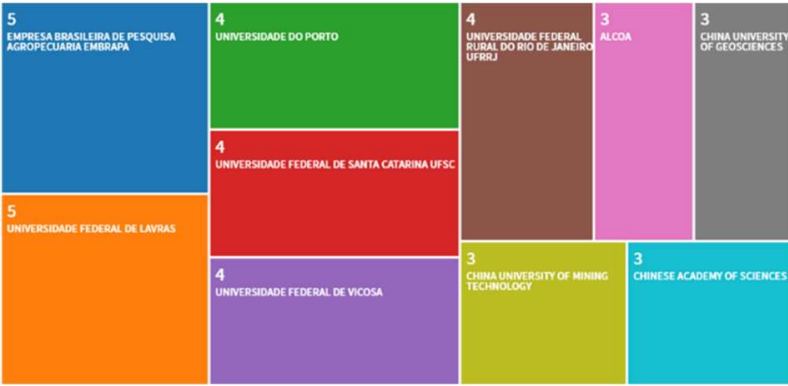

Figura 5: Publicações por organizações.

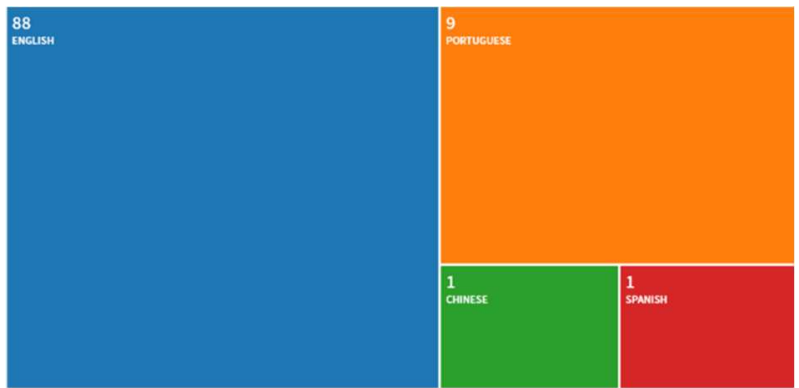

Figura 6: Idioma das publicações

Fonte: Web of Science (2020).

Como esperado, o idioma preponderante nas publicações é o inglês, sendo utilizado em quase $90 \%$ das publicações. O português aparece como segunda opção mais frequente. Tal resultado parece comum em se tratando de literatura acadêmica, visto que, além de ser o idioma mais falado do mundo, o inglês é reconhecido como o idioma oficial das relações internacionais (CLARIN, 2019).

Encerrando a análise avaliativa dos dados coletados, utilizou-se o Fator $\mathrm{H}(\mathrm{H}$-index $)$ para concluir sobre as obras de maior impacto no campo delimitado pelos temas-chave abordados neste estudo. Em um primeiro momento, levou-se em consideração as citações dentro e fora do universo de publicações investigadas, ou seja, citações realizadas por publicações que fazem parte do universo, assim como de publicações que não fazem parte, resultando nos dados apresentados pelo quadro 2 , a seguir:

Quadro 2: Fator H (H-Index) das publicações investigadas.

\begin{tabular}{|c|c|c|c|c|}
\hline Título & Autores & Título da fonte & Ano & Citações \\
\hline $\begin{array}{l}\text { Negative } \mathrm{pH} \text {, efflorescent mineralogy, and } \\
\text { consequences for environmental restoration } \\
\text { at the Iron Mountain Superfund site, } \\
\text { California }\end{array}$ & Nordstrom, DK; Alpers, CN & $\begin{array}{l}\text { PROCEEDINGS OF } \\
\text { NATIONAL ACADEMY OF } \\
\text { SCIENCES OF THE UNITED } \\
\text { STATES OF AMERICA }\end{array}$ & 1999 & 297 \\
\hline $\begin{array}{l}\text { Biotechnology and bioremediation: successes } \\
\text { and limitations }\end{array}$ & $\begin{array}{l}\text { Dua, M; Singh, A; } \\
\text { Sethunathan, N; Johri, AK }\end{array}$ & $\begin{array}{l}\text { APPLIED MICROBIOLOGY } \\
\text { AND BIOTECHNOLOGY }\end{array}$ & 2002 & 210 \\
\hline $\begin{array}{l}\text { Quality of amended mine soils after sixteen } \\
\text { years }\end{array}$ & $\begin{array}{l}\text { Bendfeldt, ES; Burger, JA; } \\
\text { Daniels, WL }\end{array}$ & $\begin{array}{l}\text { SOIL SCIENCE SOCIETY OF } \\
\text { AMERICA JOURNAL }\end{array}$ & 2001 & 101 \\
\hline $\begin{array}{l}\text { Recovery of soil organic matter, organic } \\
\text { matter turnover and nitrogen cycling in a } \\
\text { post-mining forest rehabilitation }\end{array}$ & $\begin{array}{l}\text { Banning, N. C.; Grant, C. D.; } \\
\text { Jones, D. L.; Murphy, D. V. }\end{array}$ & $\begin{array}{l}\text { SOIL BIOLOGY \& } \\
\text { BIOCHEMISTRY }\end{array}$ & 2008 & 74 \\
\hline
\end{tabular}




\begin{tabular}{|c|c|c|c|c|}
\hline chronosequence & & & & \\
\hline $\begin{array}{l}\text { Long-term distribution, mobility and plant } \\
\text { availability of compost-derived heavy metals } \\
\text { in a landfill covering soil }\end{array}$ & $\begin{array}{l}\text { Businelli, D.; Massaccesi, L.; } \\
\text { Said-Pullicino, D.; Gigliotti, } \\
\text { G. }\end{array}$ & $\begin{array}{l}\text { SCIENCE OF THE TOTAL } \\
\text { ENVIRONMENT }\end{array}$ & 2009 & 65 \\
\hline $\begin{array}{l}\text { Effects of pyrite sludge pollution on soil } \\
\text { enzyme activities: Ecological dose-response } \\
\text { model }\end{array}$ & 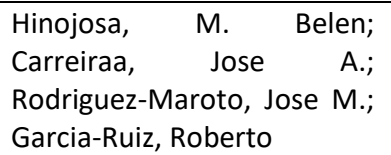 & $\begin{array}{l}\text { SCIENCE OF THE TOTAL } \\
\text { ENVIRONMENT }\end{array}$ & 2008 & 58 \\
\hline $\begin{array}{l}\text { Nematodes as indicators of soil recovery in } \\
\text { tailings of a lead/zinc mine }\end{array}$ & $\begin{array}{l}\text { Shao, Yuanhu; Zhang, } \\
\text { Weixin; Shen, Juecui; Zhou, } \\
\text { Lixia; Xia, Hanping; Shu, } \\
\text { Wensheng; Ferris, Howard; } \\
\text { Fu, Shenglei }\end{array}$ & $\begin{array}{l}\text { SOIL BIOLOGY } \\
\text { BIOCHEMISTRY }\end{array}$ & 2008 & 47 \\
\hline $\begin{array}{l}\text { Co-occurrence of 1,4-dioxane with } \\
\text { trichloroethylene in chlorinated solvent } \\
\text { groundwater plumes at US Air Force } \\
\text { installations: Fact or fiction }\end{array}$ & $\begin{array}{l}\text { Anderson, Richard H.; } \\
\text { Anderson, Janet K.; Bower, } \\
\text { Paul A. }\end{array}$ & $\begin{array}{l}\text { INTEGRATED } \\
\text { ENVIRONMENTAL } \\
\text { ASSESSMENT } \\
\text { MANAGEMENT }\end{array}$ & 2012 & 43 \\
\hline $\begin{array}{l}\text { Arbuscular mycorrhizal fungi in } \\
\text { phytoremediation of contaminated areas by } \\
\text { trace elements: mechanisms and major } \\
\text { benefits of their applications }\end{array}$ & $\begin{array}{llr}\text { Cabral, } & \text { Lucelia; } & \text { Fonseca } \\
\text { Sousa Soares, } & \text { Claudio } \\
\text { Roberto; Giachini, } \quad \text { Admir } \\
\text { Jose; Siqueira, Jose Oswaldo }\end{array}$ & $\begin{array}{lr}\text { WORLD JOURNAL } & \text { OF } \\
\text { MICROBIOLOGY } & \& \\
\text { BIOTECHNOLOGY } & \end{array}$ & 2015 & 37 \\
\hline $\begin{array}{l}\text { Petrographic, mineralogical and geochemical } \\
\text { characterization of the Serrinha coal waste } \\
\text { pile (Douro Coalfield, Portugal) and the } \\
\text { potential environmental impacts on soil, } \\
\text { sediments and surface Waters }\end{array}$ & $\begin{array}{l}\text { Ribeiro, J.; Ferreira da Silva, } \\
\text { E.; Li, Z.; Ward, C.; Flores, D. }\end{array}$ & $\begin{array}{l}\text { INTERNATIONAL JOURNAL OF } \\
\text { COAL GEOLOGY }\end{array}$ & 2010 & 37 \\
\hline $\begin{array}{l}\text { Recolonization of regenerating open forest by } \\
\text { terrestrial lizards following sand mining }\end{array}$ & TWIGG, LE; FOX, BJ & $\begin{array}{l}\text { AUSTRALIAN JOURNAL OF } \\
\text { ECOLOGY }\end{array}$ & 1991 & 28 \\
\hline $\begin{array}{l}\text { Assessment of restoration success of former } \\
\text { metal mining areas after } 30 \text { years in a highly } \\
\text { polluted Mediterranean mining area: } \\
\text { Cartagena-La Union }\end{array}$ & $\begin{array}{l}\text { Gomez-Ros, J. M.; Garcia, G.; } \\
\text { Penas, J. M. }\end{array}$ & ECOLOGICAL ENGINEERING & 2013 & 27 \\
\hline $\begin{array}{l}\text { Baseline and premining geochemical } \\
\text { characterization of mined sites }\end{array}$ & Nordstrom, D. Kirk & APPLIED GEOCHEMISTRY & 2015 & 26 \\
\hline $\begin{array}{l}\text { Arbuscular mycorrhizal fungi occurrence in } \\
\text { revegetated areas after bauxite mining at } \\
\text { Porto Trombetas, Para State, Brazil }\end{array}$ & $\begin{array}{l}\text { Caproni, AL; Franco, AA; } \\
\text { Berbara, RLL; Trufem, SB; } \\
\text { Granha, JRDD; Monteiro, AB }\end{array}$ & $\begin{array}{l}\text { PESQUISA } \\
\text { BRASILEIRA }\end{array}$ & 2003 & 25 \\
\hline $\begin{array}{l}\text { A field experiment on the use of Pistacia } \\
\text { lentiscus L. and Scrophularia canina L. subsp } \\
\text { bicolor (Sibth. et Sm.) Greuter for the } \\
\text { phytoremediation of abandoned mining áreas }\end{array}$ & $\begin{array}{l}\text { Bacchetta, G.; Cao, A.; } \\
\text { Cappai, G.; Carucci, A.; Casti, } \\
\text { M.; Fercia, M. L.; Lonis, R.; } \\
\text { Mola, F. }\end{array}$ & PLANT BIOSYSTEMS & 2012 & 24 \\
\hline $\begin{array}{l}\text { The synthetic geo-ecological environmental } \\
\text { evaluation of a coastal coal-mining city using } \\
\text { spatiotemporal big data: A case study in } \\
\text { Longkou, China }\end{array}$ & $\begin{array}{l}\text { He, Fuhong; Gu, Lijuan; } \\
\text { Wang, Tao; Zhang, Zhenhua }\end{array}$ & $\begin{array}{l}\text { JOURNAL OF CLEANER } \\
\text { PRODUCTION }\end{array}$ & 2017 & 23 \\
\hline $\begin{array}{l}\text { Galvanic interactions between metal sulfide } \\
\text { minerals in a flowing system: Implications for } \\
\text { mines environmental restoration }\end{array}$ & $\begin{array}{l}\text { Liu, Qingyou; Li, Heping; } \\
\text { Zhou, Li }\end{array}$ & APPLIED GEOCHEMISTRY & 2008 & 21 \\
\hline $\begin{array}{l}\text { Evaluation of remediation techniques in soils } \\
\text { affected by residual contamination with } \\
\text { heavy metals and arsenic }\end{array}$ & $\begin{array}{l}\text { Garcia-Carmona, } r \text { M.; } \\
\text { Romero-Freire, A.; Aragon, } \\
\text { M. Sierra; Garzon, F. J. } \\
\text { Martinez; Peinado, F. J. } \\
\text { Martin }\end{array}$ & $\begin{array}{l}\text { JOURNAL } \\
\text { ENVIRONMENTAL } \\
\text { MANAGEMENT }\end{array}$ & 2017 & 19 \\
\hline
\end{tabular}

O campo estudado possui um Fator $\mathrm{H}$ igual a 18. Dessa maneira, no quadro 2 são listadas as 18 obras de maior relevância, ranqueadas em função do seu impacto. A mais antiga das publicações é de 1991 (Recolonization of regenerating open Forest by terrestrial lizards following sand mining) e foi escrita por L. E. Twigg e B. J. Fox. Todavia, a obra de maior impacto foi escrita em 1999 por D. K. Nordstrom e C. N. Alpers: Negative $\mathrm{pH}$, efflorescent mineralogy, and consequences for environmental restoration at the Iron Mountain Superfund site, California. Foi publicada no Proceedings of the National Academy of Sciences of the United States of America e, desde então, foi citada por praticamente 300 outras publicações. D. K. Nordstrom, 
inclusive, possui outro artigo no grupo de maior impacto (Baseline and premining geochemical characterization of mined sites) se consolidando como um dos autores de maior relevância na área. Não se verificou uma concentração de publicações em determinados periódicos, sendo bem fragmentada a localização dos artigos - resultado alinhado com as observações realizadas a partir da análise da Figura 3. Nesse sentido, apesar do Brasil possuir a maioria absoluta de autoria de artigos, apenas uma das publicações de impacto ocorreu em um periódico nacional: Arbuscular mycorrhizal fungi occurrence in revegetated areas after bauxite mining at Porto Trombetas, Para State, Brazil - escrito por A. L. Caprioni e outros cinco autores e que foi publicada no periódico Pesquisa Agropecuária Brasileira. Além desta, outra publicação brasileira compõe o grupo dos trabalhos de maior impacto na temática objeto deste estudo: Arbuscular mycorrhizal fungi in phytoremediation of contaminated areas by trace elements: mechanisms and major benefits of their applications, cuja autoria é de Lucélia Cabral e outros quatro autores e foi publicado no World Journal of Microbiology \& Biotechnology, em 2015.

Em um segundo momento, levou-se em consideração as citações apenas dentro do universo de publicações investigadas, ou seja, citações realizadas por publicações que fazem parte do universo, resultando nos dados apresentados pelo quadro 3.

Quadro 3: Fator $\mathrm{H}(\mathrm{H}$-Index) das publicações investigadas.

\begin{tabular}{|l|l|l|l|l|}
\hline Título & Autores & Título da fonte & Ano & Citações \\
\hline $\begin{array}{l}\text { Quality of amended mine soils after sixteen } \\
\text { years }\end{array}$ & $\begin{array}{l}\text { Bendfeldt, ES; Burger, JA; } \\
\text { Daniels, WL SOIL SCIENCE SOCIETY OF } \\
\text { AMERICA JOURNAL }\end{array}$ & 2001 & 2 \\
\hline $\begin{array}{l}\text { Arbuscular mycorrhizal fungi occurrence in } \\
\text { revegetated areas after bauxite mining at at }\end{array}$ & $\begin{array}{l}\text { Caproni, AL; Franco, AA; } \\
\text { Berbara, RLL; Trufem, SB; } \\
\text { Porto Trombetas, Para State, Brazil }\end{array}$ & $\begin{array}{l}\text { AGROPECUARIA } \\
\text { Granha, JRDD; Monteiro, AB }\end{array}$ & 2003 & 2 \\
& & \\
\hline
\end{tabular}

Nessa nova abordagem, o campo estudado possui Fator $\mathrm{H}$ igual a 2. Duas publicações possuem fator de impacto, apenas. Pela pequena quantidade de citações entre os membros do universo investigado notase pouco interesse nas pesquisas dos mesmos (entre si). Talvez a jovialidade da temática objeto da pesquisa seja uma razão.

Tendo em vista avançar no entendimento da temática estudada e como as publicações acerca do tema têm modelado o campo da recuperação de áreas degradadas em combinação com a mineração, fez-se necessário mapear as relações e clusters formados por publicações e autores que compõem o universo de dados estudado. Dessa maneira, utilizou-se como ferramenta de visualização de redes bibliométricas o software VOSviewer version 1.6.12. Com o auxílio deste, foram elaborados mapas de acordo com os parâmetros de corte informados no quadro 1.

A figura 7, a seguir, apresenta a rede bibliométrica de coautoria, por autores, no universo de publicações investigado. Cabe observar que, em virtude da natureza exploratória deste estudo, foram incluídos todos os autores com alguma publicação, visto que apenas 24 do total de 435 autores possui mais de uma publicação. Dessa forma, elaborar a rede com somente os 24 autores limitaria a análise inicial da temática, assim como sua descrição.

Para fins de análise, deve-se observar que o tamanho da esfera de cada autor é determinado pelo seu peso em termo de citações, de maneira que quanto mais citações o autor recebeu, maior será sua esfera. 
A proximidade entre esferas de autores representa sua proximidade em termos de semântica - uma análise aprofundada sobre o conteúdo das obras desses autores, em casos assim, pode concluir se essa proximidade semântica representa afinidade intelectual. As conexões entre as esferas representam trabalho em cooperação, expressas em coautoria de obras. E, por fim, um conglomerado de esferas com a mesma cor representa um conjunto de autores interligados entre si por relações de coautoria, aqui abordados pelo software como clusters.

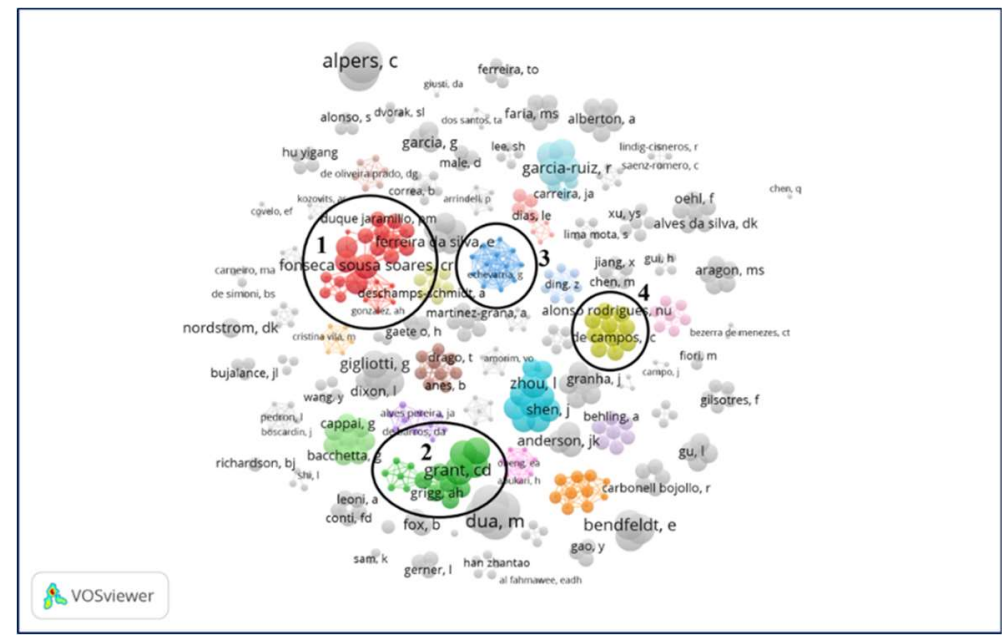

Figura 7: Rede de coautoria, por autores.

Os resultados apresentados na figura 7 mostram que foram mapeados 84 clusters de cooperação no universo de dados pesquisados. Os 4 principais se encontram circulados no mapa. O número 1 (em vermelho) é composto pela maior quantidade de autores (24) e, essencialmente, por autores brasileiros, tendo como mais citado C. R. Fonseca Sousa Soares (53). O número 2 (em verde) é composto por 16 autores, em sua maioria australianos, cujo autor de destaque é C. D. Grant, sendo citado mais de 90 vezes na rede. O cluster número 3 (em azul) é composto por 13 autores e se configura como um núcleo 'francês', com autores vinculados, em sua maioria, à Universidade de Lorraine, na França. Neste, nenhum membro se destaca em termos de citações. Por fim, o conglomerado de cooperação número 4 (em amarelo) é composto por 10 autores brasileiros e todos aparecem em condição de igualdade em termos de impacto de citações (trata-se de uma colaboração apenas em que todos os dez autores participaram de uma publicação sobre o colapso da Barragem do Fundão - MG). A partir desse ponto, os clusters têm menor composição, caracterizando o campo, de forma geral, como fragmentado e pouco conectado, em termos de colaboração. Isso se torna ainda mais claro quando se constata que os autores da obra de maior impacto (fator H), Nordstrom e Alpers, se encontram isolados (ao alto) no mapa de colaborações, não integrando nenhuma outra rede de colaboração. Por outra perspectiva, de forma complementar, uma observação evolutiva pode ser realizada a partir da interpretação da figura 8.

De início, é possível concluir que, dos clusters destacados na análise (a partir da configuração da figura 7), o que possui publicações mais antigas é o 2, caracterizado pela predominância de autores australianos. Conforme se observa que existe pouca ligação com publicações mais recentes no conglomerado, o que pode indicar uma não continuidade da temática abordada no grupo. Por outro lado, o 
cluster formado predominantemente por autores franceses se situa como o mais atual, em termos de publicações. Uma análise qualitativa detalhada das obras que compõem o cluster pode indicar uma abordagem em abertura no campo geral de estudo. A mesma percepção pode ser aplicada a todos os clusters identificados no mapa com cores em tom de amarelo. De forma geral, fica claro que existe pouca variação de escala de tempo dentro dos clusters. Outra maneira de interpretar as colaborações realizadas em torno da temática, consiste em analisar a rede bibliométrica de coautoria por organizações, conforme mostra a figura 9.

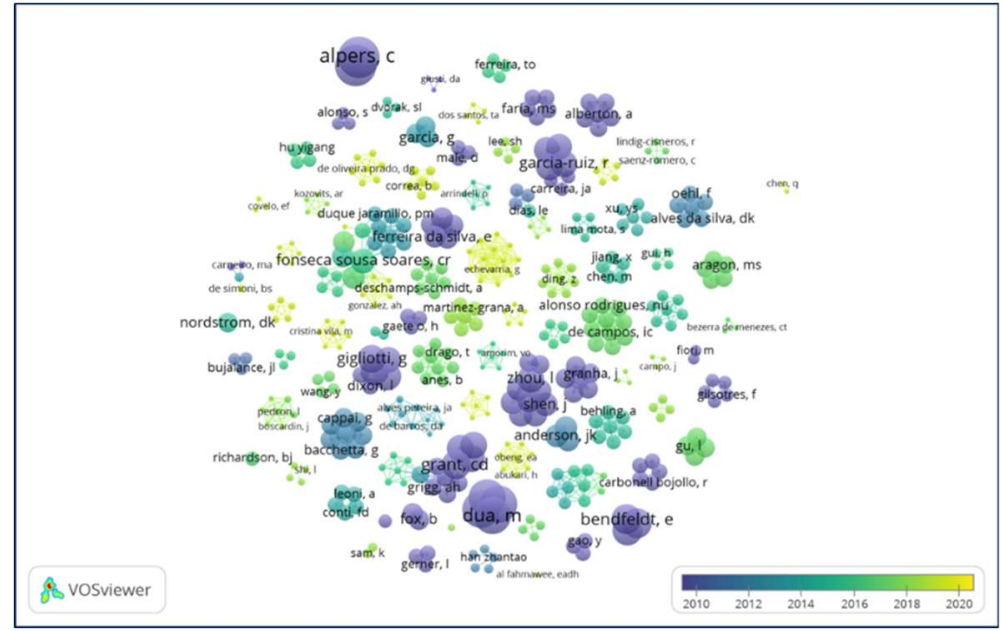

Figura 8: Rede de coautoria, por autores, com escala evolutiva.

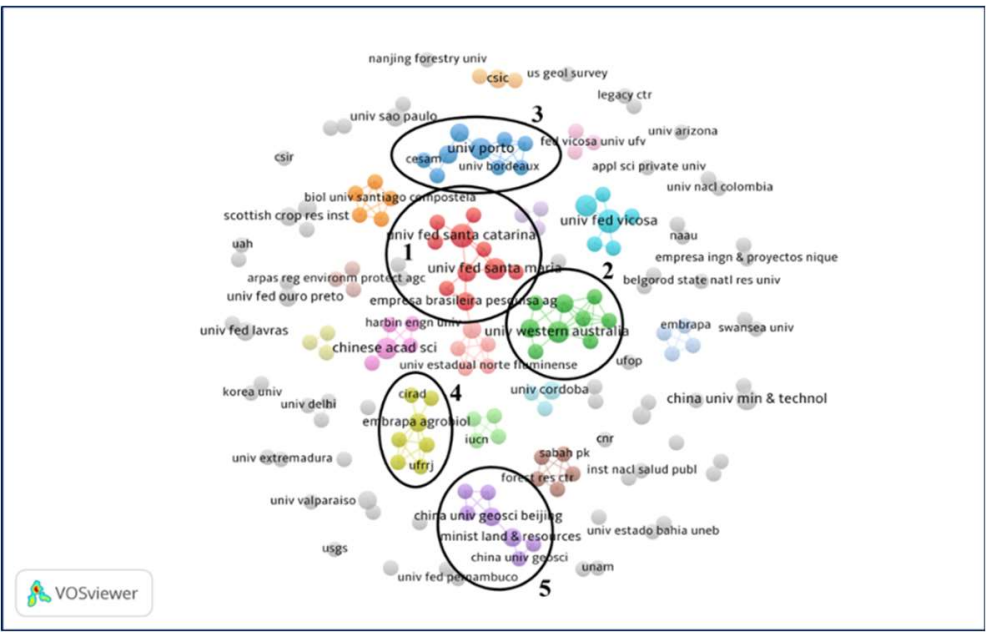

Figura 9: Rede de coautoria, por organizaçõe.

A rede de colaborações consolidada apresenta 164 organizações participando de publicações, organizadas em 61 clusters. Várias organizações brasileiras são destaque em conglomerados na rede. De forma mais pontual, optou-se por circular os 5 clusters mais representativos. O número 1 (em vermelho) é formado 10 organizações e que, quase em sua totalidade, são brasileiras (9 das 10). A Universidade Federal de Santa Catarina é a de mais destaque e com mais publicações. A maioria dos componentes desse conglomerado também se localiza na região Sul do país (a exemplo da Universidade Federal do Rio Grande do Sul e Universidade Federal de Santa Maria). O segundo cluster de maior destaque na rede (em verde) tem como expoente a University of Western Australia, sediada em Perth (Austrália Ocidental) e fundada em 1911. O cluster é composto por 9 organizações, em sua maioria também por organizações australianas. 0 terceiro cluster de maior impacto na rede (em azul) é um conglomerado essencialmente europeu. Tendo como 
destaque maior a Universidade do Porto, possui 9 componentes. Além de organizações portuguesas, também fazem parte organizações francesas (como a Universidade de Bordeaux) e australianas (University New South Wales). O quarto cluster de destaque (em amarelo), novamente, é um conglomerado de cooperação brasileiro, com 7 membros. Sem nenhuma organização com destaque elevado, é formada por duas unidades da EMBRAPA, universidades localizadas no Rio de Janeiro e outras na região Norte do país. Por fim, o último cluster dos 5 mais destacados (em roxo) é composto por, basicamente, organizações chinesas. São 7 componentes tendo como mais destacada a China University of Geosciences, formando conglomerado asiático de pesquisa na temática estudada. Dessa maneira, América, Europa, Ásia e Oceania contam com grupos de cooperação interoganizacionais bem delineados, sendo o Brasil o país com mais clusters de destaque - resultado condizente com as conclusões obtidas a partir da análise da figura 4. Partindo de tais conclusões, faz-se interessante avaliar a evolução cronológica das publicações dentro da rede. Dados sobre essa movimentação temporal se encontram na figura 10.

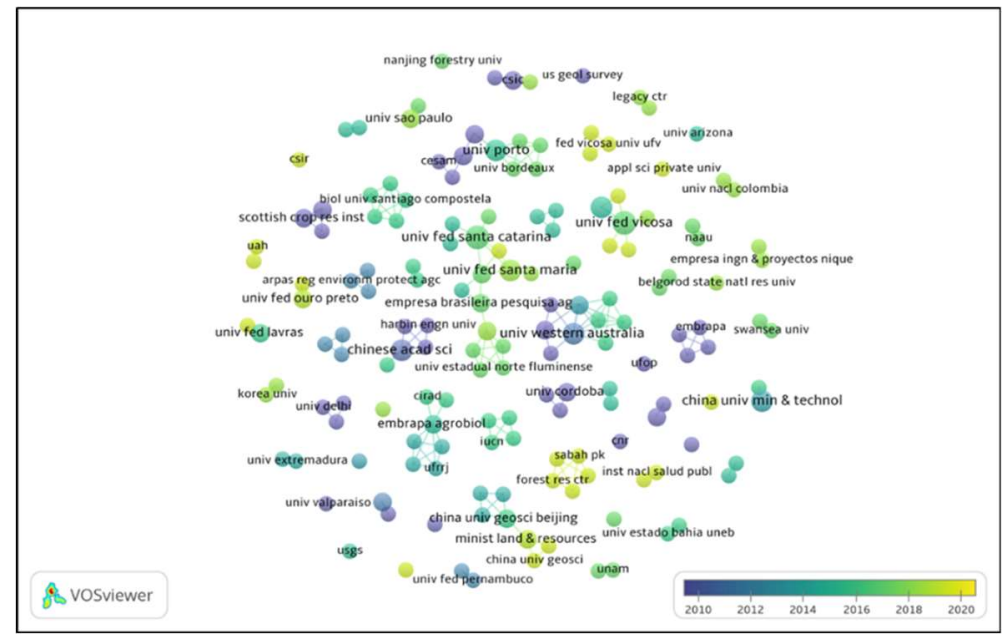

Figura 10: Rede de coautoria, por organizações, com escala evolutiva.

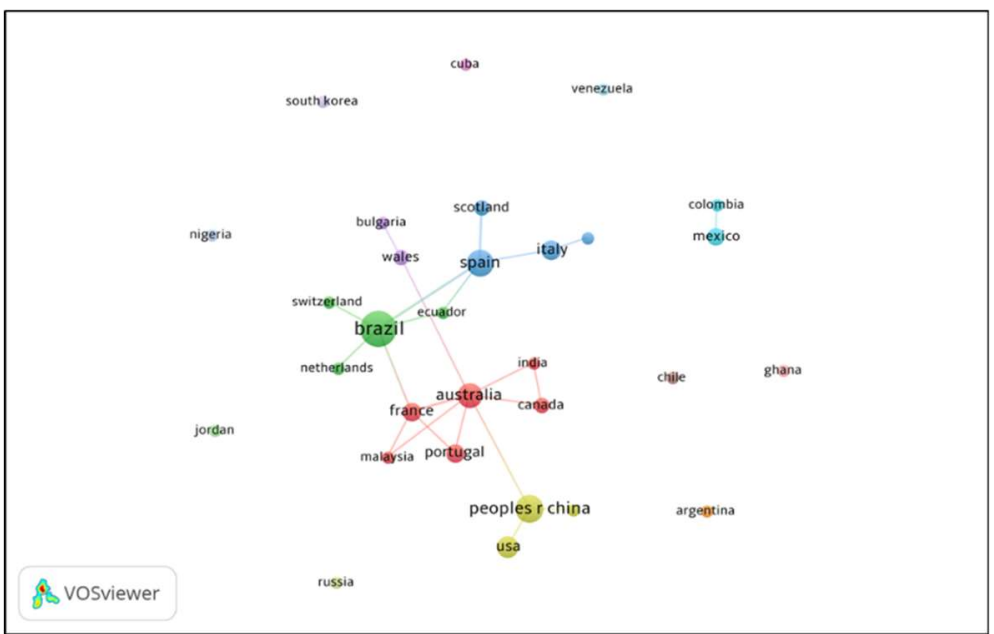

Figura 11: Rede de coautoria, por países.

Diferentemente da conclusão obtida a partir da evolução das publicações em coautoria por autores (embasada na análise da figura 8), aqui é possível observar que em todos os principais clusters as publicações não estão concentradas apenas em um curto espaço temporal. Nota-se que estudos são feitos e publicados em diferentes momentos, o que pode indicar uma continuidade de interesse pelo tema nos conglomerados 
de organizações, mesmo que essa continuidade não seja garantida pelos mesmos autores - nesse ponto, um possível indício de renovação de autoria atuante no campo. A partir disso, cabe analisar a rede de cooperação por países. Os dados sobre esse aspecto se encontram expostos na figura 11.

O mapeamento bibliométrico por países constata uma composição de 30 países e 15 clusters de cooperação. O principal conglomerado (em vermelho) é composto por 6 países. Neste a Austrália lidera em termos de publicações e é possível observar uma tendência em termos de cooperação entre países: a coautoria intercontinental, visto que o cluster tem representantes de outros continentes, além da Oceania tal característica poderá ser constatada em outros conglomerados da rede. O segundo cluster em termos de importância na rede (em verde) é composto por Brasil (o mais destacado no agrupamento), Equador, Holanda e Suiça. Em seguida (em azul), em terceiro se encontra o único cluster de destaque composto integralmente por países do mesmo continente (Europa): Espanha, Itália, Inglaterra e Suiça. Visto que a facilidade de comunicação é um aliado forte na articulação da pesquisa científica e que, certamente, foi um facilitador na realização de pesquisas à distância, uma oportunidade de investigação interessante é analisar a produção científica nesse cluster, de forma qualitativa, para observar se o 'isolamento' desse conglomerado em relação ao restante do universo de países pesquisadores se deve à características inerentes aos objetivos centrais das publicações ou se representa algum tipo de resistência em cooperar com autores e/ou organizações de outros continentes. Por fim, encerrando a avaliação relacional do estudo, elaborou-se o mapa de coocorrência de termos. O resultado está apresentado na figura 12.

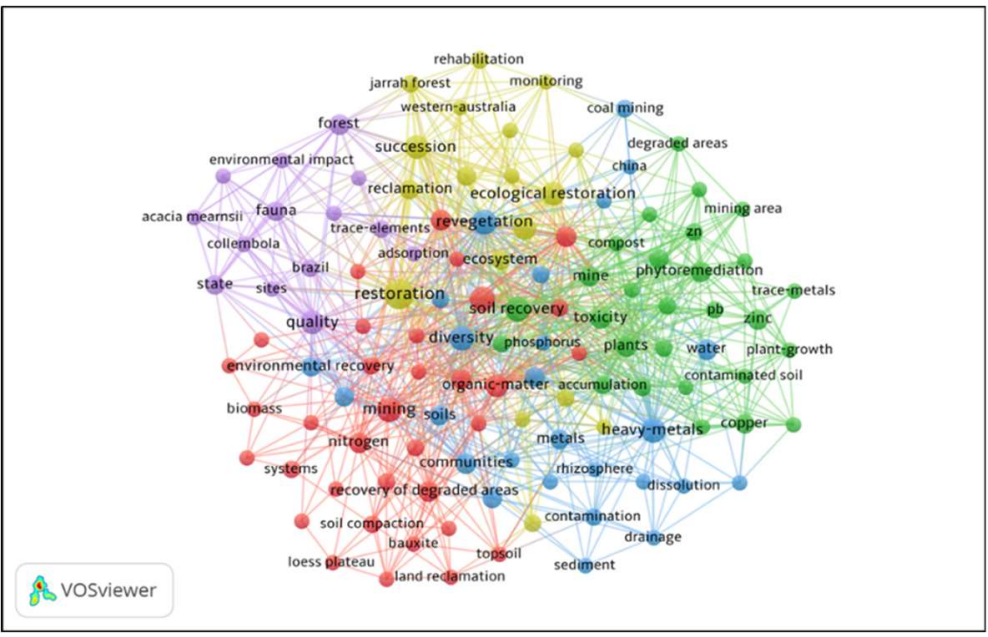

Figura 12: Rede de coocorrência de termos.

O mapa apresenta a coocorrência de palavras, ou seja, palavras que são mencionadas em conjunto nos trabalhos publicados investigados neste estudo. Assim como no mapa de coautoria, a proximidade das esferas significa uma forte relação de ocorrência e os clusters formados denotam uma similaridade semântica dos estudos - novamente, um indício de proximidade intelectual nos trabalhos a se confirmar com estudo qualitativo das obras. Para efeito de elaboração, foram considerados somente os termos com, ao menos, duas menções, resultando em um total de 120 palavras. O mapa resultante sugere a existência de 5 conglomerados de termos. Estes, a depender de estudo complementar, podem sugerir a existência de subcampos de estudo formados dentro da temática abordada neste trabalho. O primeiro mais destacado dos 
clusters (em vermelho) é composto por 34 termos. Sua composição está centrada em torno da mineração (mining). Termos como 'recuperação de áreas degradadas', 'recuperação', 'qualidade do solo', 'restauração ambiental', 'conservação', 'nitrogênio', 'compactação do solo', entre outros, compõem o conglomerado. Claramente, esse grupo de termos está fortemente associado ao conhecimento basilar que decorre do estudo da mineração, seu impacto no solo e a recuperação do mesmo. O segundo cluster mais destacado na rede (em verde) é composto por 28 termos e sua composição está centrada em torno da recuperação do solo (soil recovery). Termos como 'plantas', 'toxicidade', 'mina', 'solo contaminado', 'fitorremediação', 'crescimento da vegetação' e outros associados compõem o conglomerado. Este grupo apresenta uma abordagem mais voltada ao aspecto 'ambiental' da temática, centrando seu encadeamento nos efeitos da mineração no solo. O terceiro cluster de maior destaque na rede (em azul) é composto por 26 itens e está centrado em torno dos metais pesados. Termos como 'metais', 'poluição', 'água', 'diversidade', 'impactos', 'aço', contaminação' e 'comunidades' estão presentes no conglomerado. Nota-se uma concentração de estudo em torno do objeto da mineração e como a atividade impacta o ambiente explorado - aqui uma abordagem que discute, de forma ampla, o tema que compõe o grupo, não cncentrando a discussão, necessariamente, em elementos por demasiado técnicos. Já o cluster quarto em termos de destaque (em amarelo) é composto por 18 itens e está centrado na restauração (restauration). Termos como 'restauração ecológica', 'ecosistema', 'monitoramento', 'reabilitação' e 'sucessão' estão presentes no conglomerado. É possivel perceber uma forte relação entre temas que tratam do processo de recuperação da área degradada em si, abordando aspectos (representados nos termos) que compoem o escopo técnico da RAD. Por fim, o último cluster formado (em roxo) está centrado no tema 'qualidade' (quality) é tem em sua composição 14 itens. Termos como 'fauna', 'floresta', 'Brasil', 'geoquímica' e 'impacto ambiental' são componentes do conglomerado. Conclui-se, em esforço de dedução, por uma temática de estudo centrada em dialogar sobre a mineração e o papel do Brasil nesse cenário, ainda tendo como elementos fortes a Amazônia e os recentes desastres ambientais decorrentes de atividades de mineração. Complementarmente, a figura 13, a seguir, demonstra a rede bibliométrica de coocorrência de termos enfatizando a cronologia das publicações.

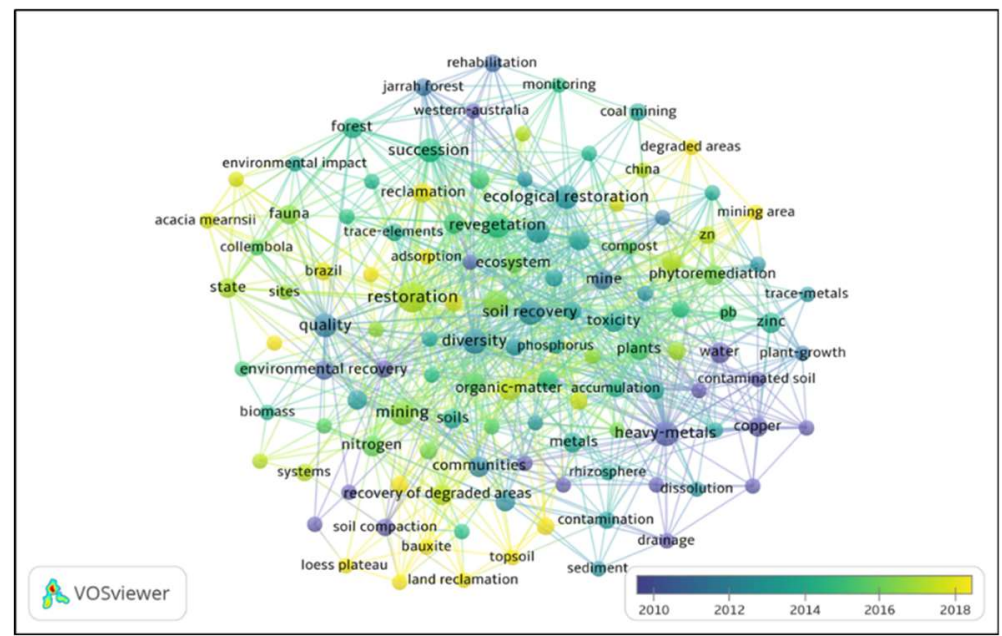

Figura 13: Rede de coocorrência de termos, com escala evolutiva.

É possível observar que o cluster 3 (metais pesados) é composto por publicações mais antigas. Isso 
pode indicar um subcampo de abertura acerca da temática estudada. Por outro lado, temas associados à restauração e mineração ganharam força a partir, em média, de 2015. Interessante perceber que o tema 'Brasil' representa uma abordagem mais recente em seu cluster. Isso, novamente, reforça o indício de que o país tem merecido destaque no desenvolvimento da temática e que os motivos podem ser os elencados na análise final da figura anterior. De maneira geral, parece haver bastante 'evolução' dentro dos cluster, ou seja, novos termos vêm sendo agregados - um sinal de que novos aportes temáticos estão ocorrendo dentro de cada conglomerado de termos.

\section{CONCLUSÕES}

Este estudo procurou apresentar o comportamento bibliométrico da produção científica internacional sobre a temática Recuperação de áreas degradadas em associação com a mineração. Como resultado do método de pesquisa já mencionado, foi possível conhecer as características da temática, elencando dados como quantidade de publicações por ano, áreas de publicação, periódicos com mais publicações, países com autores que mais publicam, organizações que mais publicam, além de analisar, via técnicas relacionais, os mapas de relações de coautoria entre autores, organizações e países. Por fim, foi possível concluir sobre os conglomerados semânticos que têm sido formados acerca do tema central deste estudo. Nesse sentido, observou-se que o Brasil, seus autores e organizações ocupam posição de destaque na produção internacional investigada.

Faz-se adequado comentar que a preocupação com a recuperação de áreas degradadas por mineração tem evoluído ao longo das últimas décadas, visando minimizar os impactos negativos, causados pela extração de minérios. O que antes se limitava ao restabelecimento das condições originais do local, hoje, busca-se desenvolver ações que contribuam para que esses impactos sejam efetivamente corrigidos e que a estabilidade e a sustentabilidade do ambiente sejam asseguradas.

No decorrer desta pesquisa, foi possível verificar, também, que os impactos causados pelas atividades da mineração é uma preocupação de cunho social e representa um desafio humano para o desenvolvimento sustentável, além disso, os danos causados ao ambiente se refletem na diminuição da cobertura verde; contaminação do solo; perda parcial ou total da fauna e flora, incluindo ecossistemas florestais; redução da quantidade e qualidade dos recursos hídricos; poluição do ar e na saúde e habitação humana ou ambos.

Por fim, os resultados desta pesquisa evidenciam que há um campo vasto de estudo a ser desenvolvido sobre o tema pesquisado. Por essa razão, sugere-se que estudos futuros desta natureza, possam ser desenvolvidos, no sentido de alimentar as bases de dados científicos.

\section{REFERÊNCIAS}

ABNT. Associação Brasileira de Normas Técnicas. NBR 13030: Elaboração e apresentação de projeto de reabilitação de áreas degradadas pela mineração. Rio de Janeiro: ABNT, 1999.
ALMEIDA, R. O. P. O; SANCHES, L. E.. Revegetação em áreas de mineração: critérios de monitoramento e avaliação do desempenho. Revista Árvore, v.29, n.1, p.47-54, 2005. DOI: https://doi.org/10.1590/S0100-67622005000100006 
ARAÚJO, E. R.. Fechamento de Minas no Brasil: Aspectos legais e conseqüências sobre o meio ambiente e populações. Rio de Janeiro: CETEM, 2016.

BALIERO, F. C.; COSTA, A. C.; OLIVEIRA, R. B.; OLIVEIRA, R.; DONAGEMMA, G. K.; ANDRADE, A. G.; CAPECHE, C. L.. Carbon stocks in mined area reclaimed by leguminous trees and sludge. Revista Árvore, v.41, n.6, 2017. DOI: https://doi.org/10.1590/1806-90882017000600010

BARRETO, M. L.. Mineração e desenvolvimento sustentável: desafios para o Brasil. Rio de Janeiro: CETEM, 2001.

BENGTSSON, J.; ANGELSTAM, P.; ELMQVIST, T.; EMANUELSSON, U.; FOLKE, C.; IHSE, M.; MOBERG, F.; NYSTROM, M.. Reserves, resilience and dynamic landscapeS. AMBIO: A Journal of the Human Environment, v.32, n.6, 2003. DOI: https://doi.org/10.1579/0044-7447-32.6.389

BRASIL. Manual de Normas e Procedimentos para Licenciamento Ambiental no Setor de Extração Mineral. Brasília: MMA, 2001.

BRASIL. Constituição da República Federativa do Brasil. Brasilia: SENADO FEDERAL, 1988.

BRASIL. Decreto n.97.632 de 10 de abril de 1989. Dispõe sobre a regulamentação do Artigo $2^{\circ}$, inciso VIII, da Lei $n^{\circ}$, 6.938 , de 31 de agosto de 1981, e dá outras providências. Brasília: DOU, 1989.

CHAER, G. M.; RESENDE, A. S.; CAMPELLO, E. F. C.; FARIA, S. M.; BODDEY, R. M.. Nitrogen-fixing legume tree species for the reclamation of severely degraded lands in Brazil. Tree Physiology, v.31, n.2, p.139-149, 2011. DOI: https://doi.org/10.1093/treephys/tpq116

FARIAS, T.. Obrigações de recuperar áreas degradadas por mineração têm contornos peculiares. Consultor Jurídico, 2016.

FEPAM. Fundação Estadual de Proteção Ambiental. Termo de Referência: Relatório de Controle Ambiental e Plano de Controle Ambiental - RCA/PCA Unificados. Porto Alegre: FEPAM, 2012.

GIL, A. C.. Métodos e técnicas de pesquisa social. 6 ed. São Paulo: Atlas, 2008.

HIRSCH, J. E.. An index to quantify an individuals scientific research output. Proceedings of the National Academy of Sciences of the United States of America, v.102, n.46, p.16569-16572, 2005. DOI: https://doi.org/10.1073/pnas.0507655102

KOBIYAMA, M.; MINELLA, J. P. G.; FABRIS, R.. Áreas degradadas e sua recuperação. Informe Agropecuário, v.22, n.210, p.10-17, 2001.

KOSEOGLU, M. A.. Growth and structure of authorship and co-authorship network in the strategic management realm: Evidence from the Strategic Management Journal. Business Research Quarterly, v.19, p.153-170, 2016. DOI: https://doi.org/10.1016/i.brq.2016.02.001
LIMA, K. D. R.. Avaliação de espécies arbóreas e técnicas de plantio para recuperação de áreas degradadas por extração de piçarra na Caatinga-RN. Dissertação (Mestrado em Ciência do Solo) - Universidade Federal Rural do Semi-Árido, Mossoró, 2012.

LOPES, V. G.. Dinâmica nutricional em um povoamento de Pinus taeda L., Rio Grande do Sul - Brasil. Tese (Doutorado em Engenharia Florestal) - Universidade Federal de Santa Maria, Santa Maria, 2013.

MACHADO, I. F.. O meio ambiente e a mineração. In: BARBOZA, F. L. M.; GURMENDI, A. C.. Economia mineral do Brasil. Brasília: DNPM, 1995.

MARCUS, J. J.. Mining Environmental Handbook: Effects of Mining on the Environment and American Environmental Controls on Mining. Londres: Imperial College Press, 1997.

MECHI, A.; SANCHES, D. L.. Impactos ambientais da mineração no Estado de São Paulo. Estudos Avançados, v.24, n.68, p.209-220, 2010. DOI:

https://doi.org/10.1590/S0103-40142010000100016

MOREIRA, H. F.. O desenvolvimento sustentável no contexto do setor mineral brasileiro. Monografia (Especialização em Gestão Ambiental) - Universidade Federal do Rio de Janeiro, Rio de Janeiro, 2002.

MORETTO, R. L.. Análise dos efeitos da vegetação na proteção de talude rodoviários e proposição de alternativas de revegetação na BR-386. Dissertação (Mestrado em Engenharia Civil) - Universidade Federal do Rio Grande do Sul, Porto Alegre, 2012.

MOURA, D. J.. Recuperação de áreas degradadas pela mineração. Monografia (Bacharelado em Tecnologia em Mineração) - Universidade estadual de Goiás, Niquelândia, 2015.

NERI, A. C.; SÁNCHEZ, L. E.. Guia de boas práticas de recuperação ambiental em pedreiras e minas de calcário. São Paulo: ABGE, 2012.

PARROTTA, J. A.; KNOWLES, O. H.. Restoring tropical forests on lands mined for bauxite: examples from the Brazilian Amazon.Ecological Engineering, v.17, n.2, p.219-239, 2001. DOI: http://dx.doi.org/10.1016/S0925-8574(00)00141-5

PEREIRA, A. R.. Controle e Recuperação de Processos Erosivos com Técnicas de Bioengenharia. In: SIMPÓSIO NACIONAL DE CONTROLE DE EROSÃO, 7. Anais. 2001.

RESENDE, A. S.; CHAER, G. M.. Manual para recuperação de áreas degradadas por extração de piçarra na Caatinga. Seropédica: Embrapa Agrobiologia, 2010.

SALES, F. C. V.. Revegetação de área degradada da caatinga por meio da semeadura ou transplantio de mudas de espécies arbóreas em substrato enriquecido com matéria orgânica. Dissertação (Mestrado em Zootecnia) Universidade Federal de Campina Grande, Patos, 2008.

SHRESTHA, R. K.; LAL, R.. Carbon and nitrogen pools in reclaimed land under forest and pasture ecosystems in Ohio, USA. Geoderma, v.157, n.3, p.196-205, 2010. DOI: http://doi.org/10.1016/i.geoderma.2010.04.013 
SILVA, L. C. R.; CORREA, R. S.; DOANE, T. A.; PEREIRA, E. I. P.; HORWATH, W. R.. Unprecedented carbon accumulation in mined soils: the synergistic effect of resource input and plant species invasion.Ecological Applications, v.23, n.6, 2013. DOI: http://dx.doi.org/10.1890/12-1957.1
TATSCH, G. L.. Recuperação de uma área degradada através do método de nucleação, Santa Margarida do Sul. São

Gabriel: Universidade Federal do Pampa, 2011

VAN ECK, N. J.; WALTMAN, L.. Citation-based clustering of publications using CitNetExplorer and VOSviewer.

Scientometrics, v.111, p.1053-1070, 2017. DOI:

https://doi.org/10.1007/s11192-017-2300-7

A CBPC - Companhia Brasileira de Produção Científica (CNPJ: 11.221.422/0001-03) detém os direitos materiais desta publicação. Os direitos referem-se à publicação do trabalho em qualquer parte do mundo, incluindo os direitos às renovações, expansões e disseminações da contribuição, bem como outros direitos subsidiários. Todos os trabalhos publicados eletronicamente poderão posteriormente ser publicados em coletâneas impressas sob coordenação da Sustenere Publishing, da Companhia Brasileira de Produção Científica e seus parceiros autorizados. Os (as) autores (as) preservam os direitos autorais, mas não têm permissão para a publicação da contribuição em outro meio, impresso ou digital, em português ou em tradução. 